\title{
Prevalence of bacteria and fungi in samples of cornea preservation fluid
}

Grażyna Broniek ${ }^{1}$, Ewa Langwińska-Wośko ${ }^{1,2}$, Małgorzata Sybilska ${ }^{1}$, Jerzy Szaflik ${ }^{1}$, Jacek P. Szaflik ${ }^{1,2}$, Marta Wróblewska ${ }^{3,4}$

\begin{abstract}
${ }^{1}$ SPKSO Ophthalmic University Hospital, Medical University of Warsaw, Warsaw, Poland

${ }^{2}$ Department of Ophthalmology, Medical University of Warsaw, Warsaw, Poland ${ }^{3}$ Department of Dental Microbiology, Medical University of Warsaw, Warsaw, Poland ${ }^{4}$ Department of Microbiology, Central Clinical Hospital, Warsaw, Poland
\end{abstract}

Submitted: 22 October 2015

Accepted: 19 February 2016

Arch Med Sci 2018; 14, 3: 541-546

DOI: https://doi.org/10.5114/aoms.2016.58927

Copyright @ 2016 Termedia \& Banach

\section{Abstract}

Introduction: Recipients of corneal transplants are at risk of healthcare-associated infections, which, apart from other causes of surgical site infections, may also occur as a result of the transfer of infected corneal tissue. In this study we assessed the risk of bacterial and fungal infections based on the results of routine microbiological testing of cornea preservation fluid samples.

Material and methods: We examined a total of 725 samples of corneal preservation fluid, obtained during a period of 3 years (2011-2013). Corneal preservation fluid samples were cultured and identified in accordance with standard microbiological methods.

Results: The analysis comprised 725 samples of corneal preservation fluid, of which $32(4.4 \%)$ samples tested positively in microbiological cultures. In total, 34 strains of bacteria and fungi were cultured. Gram-positive bacteria, Gram-negative bacteria and fungi comprised $85.3 \%, 8.8 \%$ and $5.9 \%$ of these strains, respectively. Analysis of the susceptibility of the cultured bacterial isolates to gentamicin was also performed, as this antibiotic is present in the composition of corneal preservation fluid. Among the cultured bacterial strains, $10(33.3 \%)$ were resistant to gentamicin. None of the 32 patients who received a cornea stored in preservation fluid contaminated with bacteria and/or fungi demonstrated infectious complications in the surgical site within 1 year following cornea transplantation.

Conclusions: We postulate that perioperative antibiotic prophylaxis in cornea transplant recipients is important in preventing bacterial infections derived from the donor cornea. We believe that the addition of an antifungal agent to commercially available cornea preservation fluids should also be considered.

Key words: cornea transplantation, healthcare-associated infections, antibiotics, cornea preservation media, bacteria, fungi.

\section{Introduction}

Recipients of corneal transplants are at risk of healthcare-associated infectious complications from these procedures [1]. The frequency with which postoperative endophthalmitis occurs has remained unchanged over the past 20 years. Intraocular procedures are affected by infectious

\author{
Corresponding author: \\ Marta Wróblewska MD, PhD \\ Department \\ of Dental Microbiology \\ Medical University \\ of Warsaw \\ 1a Banacha St \\ 02-097 Warsaw, Poland \\ Phone: +48 225991777 \\ Fax: +48 225991778 \\ E-mail: mwroblewska@ \\ wum.edu.pl
}


complications in around $0.08 \%$ of cases, which is relatively low when compared to procedures in other medical fields. This prevalence in ophthalmology depends on the specific surgical procedures and remains at between $0.08 \%$ and $0.77 \%$ for penetrating keratoplasty (PKP) [2]. Acute cases of postoperative intraocular infections may occur within 6 weeks following the procedure, usually developing within the first few days. Apart from standard causes of infections which apply to all ophthalmological procedures, corneal transplants are also at risk of infection following the transfer of infected corneal tissue $[3,4]$. In this study we assessed the risk of developing bacterial and fungal infections based on the results of routine microbiological testing of corneal preservation fluid samples.

\section{Material and methods}

The material comprised samples of corneal preservation fluid (Eusol C, Alchimia, Padova, Italy) routinely obtained during consecutive procedures of cornea transplantation, performed at the SPKSO Ophthalmic University Hospital (Medical University of Warsaw, Poland) in the period 2011-2013. Samples were taken during surgery, immediately before transplantation of the cornea, while maintaining all aseptic precautions.

In total, 725 cornea transplant procedures were performed in this 3-year period (2011-2013). Therefore, 725 cornea preservation fluid samples were aseptically obtained during surgery and sent for bacteriological and mycological culture testing.

Samples of the corneal preservation fluid were cultured according to standard microbiological methods. Bacteriological cultures were grown on blood agar, Columbia agar and MacConkey agar, while for mycological cultures, Sabouraud's medium was used. Inoculated plates were incubated at $35^{\circ} \mathrm{C}$ for $48 \mathrm{~h}$, while mycological cultures were incubated at $30^{\circ} \mathrm{C}$ and $35^{\circ} \mathrm{C}$ and observed for 7 days.

Identification and susceptibility testing of the cultured isolates was done using the automated VITEK 2 Compact system (bioMerieux). Additionally, special tests were performed for detection of the following resistance mechanisms: methicillin susceptibility of staphylococci, macrolides, lincosamides, streptogramins $B\left(M L S_{B}\right)$ resistance pattern of Gram-positive cocci, and detection of enzyme production by Gram-negative rods - extended spectrum $\beta$-lactamase (ESBL), metallo- $\beta$-lactamase (MBL) and Klebsiella pneumoniae carbapenemase (KPC). Testing was done according to the recommendations of the Polish National Reference Centre for Susceptibility of Microorganisms (KORLD) and the European Committee on Antimicrobial Susceptibility Testing (EUCAST) [5].
Methicillin susceptibility of the Staphylococcus spp. strains was tested using a disk diffusion technique with a cefoxitin $(30 \mu \mathrm{g})$ disk. Detection of $\mathrm{MLS}_{B}$ resistance mechanism of Gram-positive cocci was performed with a disk diffusion technique, using erythromycin (15 $\mu \mathrm{g})$ and clindamycin $(2 \mu \mathrm{g})$ disks. High-level aminoglycoside resistance (HLAR) in enterococci was assessed using gentamicin $(30 \mu \mathrm{g})$ and streptomycin $(300 \mu \mathrm{g})$ disks. Detection of ESBL, MBL and KPC enzyme production by cultured Gram-negative rods was done using a double disk diffusion technique (using clavulanic acid $(10 \mu \mathrm{g}), 10 \mu \mathrm{l}$ of $0.5 \mathrm{M}$ EDTA and boronic acid $(300 \mu \mathrm{g})$ as inhibitors of ESBL, MBL and KPC enzymes, respectively).

Isolates of the Candida spp. yeast-like fungi were cultured on Sabouraud's agar, and thereafter identified using the automated VITEK 2 Compact (bioMerieux) system. Susceptibility testing of these strains was done using the automated VITEK 2 Compact (bioMerieux) system and commercially available kits based on the microdilution technique - Fungitest (Bio-Rad) and Integral System Yeast Plus (Liofilchem). Moulds of the genus Aspergillus were cultured on Sabouraud's agar, incubated at $30^{\circ} \mathrm{C}$ for 7 days and identified by morphology of the colonies and microscopy.

Medical records of the recipients of the cornea transplants for whom corneal preservation fluid samples obtained during surgery tested positively for bacteria or fungi were analyzed regarding their risk of healthcare-associated infections within at least 1 year after transplantation.

\section{Results}

The analysis comprised 725 samples of corneal preservation fluid, obtained in the period 2011-2013, out of which 32 (4.4\%) samples tested positively in microbiological cultures. In total, 34 strains of bacteria and fungi were cultured. The results of the microbiological cultures of the samples are shown in Table I.

Among the 34 strains of cultured microorganisms, Gram-positive bacteria comprised 85.3\%, Gram-negative bacteria $8.8 \%$, and fungi $5.9 \%$ (Table II).

Staphylococci were dominant among the Grampositive bacteria (18/29 (62.1\%) isolates), including coagulase-negative species (14/18 (77.8\%)) and Staphylococcus aureus (4/18 (22.2\%)). Resistance to methicillin was detected in 6/14 (42.9\%) isolates of the coagulase-negative staphylococci (MRCNS) and 2/4 (50.0\%) of the S. aureus (MRSA) strains. The mechanism of resistance $M_{L} S_{B}$ was detected in 5 of these strains -4 strains of Staphylococcus epidermidis and 1 strain of Staphylococcus hominis. Enterococci constituted 8/29 (27.6\%) strains of the cultured Gram-positive bacteria. Among these strains, only 1 isolate (Enterococcus 
Table I. Results of microbiological culture of cornea preservation fluid samples in the period 2011-2013 $(n=725)$

\begin{tabular}{|lccccc|}
\hline Year & \multicolumn{2}{c}{ Cornea preservation fluid } & & Total & $\begin{array}{c}\text { Percentage of positive } \\
\text { culture results (\%) }\end{array}$ \\
\cline { 2 - 4 } & $\begin{array}{c}\text { Number of negative } \\
\text { culture results }\end{array}$ & $\begin{array}{c}\text { Number of positive } \\
\text { culture results }\end{array}$ & & \\
\hline 2011 & 266 & 18 & 284 & $18 / 284(6.3)$ \\
\hline 2012 & 231 & 8 & 239 & $8 / 239(3.4)$ \\
\hline 2013 & 196 & 6 & 202 & $6 / 202(3.0)$ \\
\hline Total & 693 & 32 & 725 & $32 / 725(4.4)$ \\
\hline
\end{tabular}

Table II. Bacteria and fungi isolated from samples of cornea preservation fluid $(n=32)$

\begin{tabular}{|c|c|c|c|c|c|}
\hline Bacteria/fungi & 2011 & 2012 & 2013 & Total & Percentage \\
\hline Staphylococcus epidermidis & 8 & & 1 & 9 & 26.5 \\
\hline Enterococcus faecalis & 4 & 3 & & 7 & 20.5 \\
\hline Staphylococcus aureus & 1 & 3 & & 4 & 11.6 \\
\hline Staphylococcus hominis & & & 2 & 2 & 5.8 \\
\hline Staphylococcus salivarius & & & 2 & 2 & 5.8 \\
\hline Staphylococcus warneri & 1 & & & 1 & 3.0 \\
\hline Streptococcus agalactiae & 1 & & & 1 & 3.0 \\
\hline Enterococcus avium & & 1 & & 1 & 3.0 \\
\hline Corynebacterium spp. & 1 & & & 1 & 3.0 \\
\hline Clostridium perfringens & & 1 & & 1 & 3.0 \\
\hline Enterobacter cloacae & 1 & & & 1 & 3.0 \\
\hline Cronobacter sakazakii & & & 1 & 1 & 3.0 \\
\hline Brevundimonas diminuta & 1 & & & 1 & 3.0 \\
\hline Candida albicans & & 1 & 1 & 2 & 5.8 \\
\hline Total & 18 & $9^{*}$ & $7^{\star \star}$ & 34 & 100.0 \\
\hline
\end{tabular}

${ }^{\star}$ One sample-mixed flora isolated: Clostridium perfringens and Enterococcus avium; ${ }^{\star *}$ one sample - mixed flora isolated: Staphylococcus hominis and Candida albicans.

avium) did not show high-level resistance to aminoglycosides. Among the 7 strains of Enterococcus faecalis, 5 were HLAR strains and 2 were HLSR (high level streptomycin resistance) strains.

The following Gram-negative rods were cultured from the tested samples (1 isolate of each): Enterobacter cloacae, Cronobacter sakazakii (previous name Enterobacter sakazakii) and Brevundimonas diminuta (previous name Pseudomonas diminuta), susceptible to tested antimicrobials.

Two strains of yeast-like fungi (both Candida albicans) were cultured, both susceptible to fluconazole. Two samples revealed mixed cultures - Clostridium perfringens and Enterococcus avium, Staphylococcus hominis and Candida albicans.

Analysis of the susceptibility of cultured bacterial isolates to gentamicin was performed due to the presence of this antibiotic in the composition of corneal preservation fluid (Eusol C). The results are shown in Table III. Susceptibility to gentamicin was not tested for 2 cultured bacterial strains (Streptococcus agalactiae and Clostridium perfringens) for which the testing of gentamicin susceptibility is not justified therapeutically. Among the cultured bacterial strains, 20 (66.7\%) were susceptible to gentamicin (including 2 strains of Enterococcus faecalis HLSR), and 10 (33.3\%) were resistant to gentamicin.

The mean time period from the death of the donor to procurement of the cornea, in the cases with positive results for microbiological cultures of the corneal preservation fluid samples, was $9 \mathrm{~h} 7 \mathrm{~min}$, with a very wide range (from $15 \mathrm{~min}$ to $18 \mathrm{~h} 20 \mathrm{~min}$ ).

None of the 32 patients who received a cornea stored in preservation fluid contaminated with bacteria and/or fungi experienced infectious complications in the surgical site within 1 year after cornea transplantation. 
Table III. Susceptibility to gentamicin of bacteria isolated from samples of cornea preservation fluid $(n=30)$

\begin{tabular}{|c|c|c|}
\hline \multirow[t]{2}{*}{ Bacteria/fungi } & \multicolumn{2}{|c|}{ Gentamicin } \\
\hline & Susceptibility & Resistance \\
\hline $\begin{array}{l}\text { Staphylococcus aureus } \\
\text { MSSA }\end{array}$ & 2 & 0 \\
\hline $\begin{array}{l}\text { Staphylococcus aureus } \\
\text { MRSA }\end{array}$ & 2 & 0 \\
\hline $\begin{array}{l}\text { Staphylococcus } \\
\text { epidermidis MSCNS }\end{array}$ & 3 & 0 \\
\hline $\begin{array}{l}\text { Staphylococcus } \\
\text { epidermidis MSCNS, } \\
\text { MLSB }\end{array}$ & 1 & 0 \\
\hline $\begin{array}{l}\text { Staphylococcus } \\
\text { epidermidis MRCNS }\end{array}$ & 1 & 1 \\
\hline $\begin{array}{l}\text { Staphylococcus } \\
\text { epidermidis MRCNS, } \\
\text { MLS }_{B}\end{array}$ & 1 & 2 \\
\hline $\begin{array}{l}\text { Staphylococcus } \\
\text { hominis MSCNS }\end{array}$ & 1 & 0 \\
\hline $\begin{array}{l}\text { Staphylococcus } \\
\text { hominis MRCNS, } \mathrm{MLS}_{\mathrm{B}}\end{array}$ & 0 & 1 \\
\hline $\begin{array}{l}\text { Staphylococcus } \\
\text { salivarius MSCNS }\end{array}$ & 2 & 0 \\
\hline $\begin{array}{l}\text { Staphylococcus } \\
\text { warneri MSCNS }\end{array}$ & 1 & 0 \\
\hline Enterococcus avium & 1 & 0 \\
\hline $\begin{array}{l}\text { Enterococcus faecalis } \\
\text { HLAR }\end{array}$ & 0 & 5 \\
\hline $\begin{array}{l}\text { Enterococcus faecalis } \\
\text { HLSR }\end{array}$ & 2 & 0 \\
\hline Corynebacterium spp. & 1 & 0 \\
\hline Enterobacter cloacae & 0 & 1 \\
\hline Cronobacter sakazakii & 1 & 0 \\
\hline $\begin{array}{l}\text { Brevundimonas } \\
\text { diminuta }\end{array}$ & 1 & 0 \\
\hline Total & 20 & 10 \\
\hline
\end{tabular}

\section{Discussion}

Cornea transplantation entails the problem of cornea storage by guaranteeing viability and consistency of the corneal epithelium and at the same time minimizing the risk of bacterial or fungal contamination. The first reported cornea transplantation was performed in 1906; however, the development of eye tissue banks only became possible in the 1950s when antibiotics became available [6]. During the 1960s, corneas destined for transplantation were stored in so-called humid chambers for a period no longer than 2 days. Only 10 years later were cornea storage methods that are currently employed implemented - storage in a liquid medium kept at fridge temperature [6].
Low temperatures and the addition of an antibiotic (gentamicin \pm streptomycin) allow for the storage of corneas for up to 2 weeks, from the moment of their procurement from a donor to their transplantation to the recipient.

Cornea preservation fluids contain many nutrients, such as glucose, amino acids, mineral salts and vitamins, which protect corneal cells. However, such a rich composition of these fluids also favors their contamination by bacteria and/or fungi. In recent years, multidrug-resistant (MDR) strains of microorganisms have been increasingly isolated from both hospitalized patients, as well as patients with no history of hospital stay. This means that among the bacteria contaminating cornea preservation fluids, there might be strains resistant to gentamicin, which is added to these compounds (e.g. Eusol C $-0.1 \mathrm{mg} / \mathrm{ml}$ ). Baer et al. showed that the addition of gentamicin into corneal preservation fluid might not be an effective method for inhibition of the replication of Streptococcus viridans [7]. They described 3 cases of endophthalmitis in patients who received corneas stored in fluid contaminated with such bacteria, despite gentamicin being added to the storage medium [7]. Similarly, Fong et al. noticed that despite the fact that the addition of gentamicin caused a drop in the frequency of contamination of corneal preservation fluids from $43 \%$ to $13 \%$, it did not eliminate the contamination of these media with staphylococci, streptococci and fungi [8].

Amongst bacteria, the most common causes of infectious complications following cornea transplantation are Gram-positive cocci (staphylococci, Streptococcus pneumoniae, Streptococcus agalactiae, Streptococcus viridans and enterococci) [8-11].

In our study, 32/725 (4.4\%) of the corneal preservation fluid (Eusol C) samples tested positively for bacteriological or mycological cultures. During the period of 3 years we gradually observed a decrease in this occurrence $-6.3 \%$ of positive culture results were found in 2011, 3.4\% in 2012 and $3.0 \%$ in 2013 . No possible cause for this difference could be identified however. Overall, Gram-positive bacteria comprised over $85 \%$ of the isolated strains, while Gram-negative bacteria comprised almost $9 \%$ and fungi close to $6 \%$. This means that gentamicin was not effective in the inhibition of bacterial replication in these samples during cornea storage, which is in agreement with other reports in the literature $[7,8]$. Contamination of these samples during their sampling for bacteriological tests is highly unlikely, as this was performed in the operating theatre during surgery, with adherence to all aseptic precautions. Among those isolates $14 / 34$ (41.2\%) showed natural or acquired resistance to gentamicin (e.g. Strepto- 
coccus agalactiae, Clostridium perfringens, Candida albicans), while staphylococci and enterococci predominated among the other strains against which aminoglycoside is usually not effective in monotherapy. Strains of enterococci were relatively numerous in our study, comprising 8/34 (23.5\%) of all isolates from the corneal preservation fluid samples. It should be emphasized that 5 of these were HLAR strains, resistant to the gentamicin concentration in the Eusol C fluid. This emphasizes the role of antibiotic prophylaxis in cornea transplantation surgery, to minimize the risk of surgical site infections in cornea recipients.

According to the literature, the Gram-negative rods that are most commonly isolated from donor corneas are Pseudomonas aeruginosa, Enterobacter spp. and Serratia marcescens [12-14]. Morel et al. described the contamination of 28 corneas (an additional 70 were discarded) because of the contamination of trypan blue solution with a strain of Burkholderia cepacia in the eye tissue bank [15].

In our study Gram-negative rods comprised 3 isolates (8.8\%). Two strains of Enterobacter spp. were cultured-E. sakazakii (present name: Cronobacter sakazakii) and E. cloacae (a strain resistant to gentamicin), as well as 1 strain of Pseudomonas diminuta (present name: Brevundimonas diminu$t a)$. No infectious complications were observed in the recipients of the corneas stored in these fluids.

Other bacteria, which are relatively rarely isolated from donors' corneas, are Corynebacterium spp., Bacillus spp. and Neisseria spp. [14]. In our study a strain of Corynebacterium spp. was isolated from 1 sample.

According to the literature, fungal keratitis of transplanted corneas is usually caused by fungi of the genus Candida (C. albicans and C. glabrata), and more rarely by moulds of Aspergillus spp. [9, $16,17]$. There are reports of keratitis or endophthalmitis caused by documented transmission of C. albicans from a donor to a recipient $[8,18,19]$.

Frequency of post-transplantation keratitis caused by yeast-like fungi ranges from $0.6 \%$ to as high as 25.0\% [20-22]. Ritterband et al. demonstrated the presence of fungi in cultures of $7 / 533$ (1.3\%) cornea rims [22]. The authors also examined the usefulness of adding voriconazole $(0.1 \mathrm{mg} / \mathrm{ml})$ to the corneal preservation fluid. Cultures of the samples of corneal preservation fluid containing this drug were negative, with no observed toxicity for epithelial cells of the corneas stored in these fluids. In our study, 2 strains of C. albicans were cultured, comprising $5.9 \%$ of the isolates from all culture-positive samples of corneal preservation fluid during the 3-year period. This means that in the analyzed material fungi were rare contaminants of corneal preservation fluid.
It should be noted that apart from bacteria and fungi, other microorganisms may cause postoperative complications, e.g. Demodex mites are more prevalent in immunocompromised patients than in healthy persons, and they may be linked to keratitis, but their role in cornea transplant recipients is unknown [23].

Human corneal epithelium contains different populations of antigen-presenting cells (APC), including dendritic cells (DC), which mediate corneal immunity [24]. Infectious agents, including bacteria and fungi, may cause their apoptosis, which in turn will impair their presentation of foreign antigens [25]. This pathomechanism may further contribute to immunosuppression and increased susceptibility of the transplanted cornea to secondary infections [25].

Hassan et al. found that in 121 cases of endophthalmitis present in cornea transplant recipients, where cultures were available for both the donor and the recipient, 59 (48.8\%) of the cases had identical isolated strains [9]. These results indicate that routine cultures of corneal preservation fluid may be useful in the choice of empiric therapy for patients with infectious complications following cornea transplantation. However, in our study, none of the 32 patients who received a cornea stored in culture-positive contaminated fluid developed any symptoms of surgical site infection during the 1-year observation period. This may be the result of the effectiveness of antibiotic prophylaxis administered locally in these patients. Hopefully, novel techniques for cornea preservation will further decrease the risk of infectious complications in cornea recipients.

In conclusion, we postulate that perioperative antibiotic prophylaxis in cornea transplant recipients is important for the prevention of bacterial infections derived from the donor cornea. However, it was surprising that as many as $33.3 \%$ of the isolates are gentamicin-resistant bacterial strains, since corneal preservation fluids contain this antibiotic. This finding may be of clinical importance. Furthermore, we believe that the addition of an antifungal agent in the commercially available corneal preservation fluids should be considered.

\section{Conflict of interest}

The authors declare no conflict of interest.

\section{References}

1. Duran Ospina P. The complications after keratoplasty. In: Keratoplasties - surgical techniques and complications. Mosca L (ed.). 2012; 101-18. www.intechopen.com.

2. Chen JY, Jones MN, Srinivasan S, Neal TJ, Armitage WJ, Kave SB; NHSBT Ocular Tissue Advisory Group and Contributing Ophthalmologists (OTAG Audit Study 18). 
Endophthalmitis after penetrating keratoplasty. Ophthalmology 2015; 122: 25-30.

3. Wilhelmus KR, Hassan SS. The prognostic role of donor corneoscleral rim cultures in corneal transplantation. Ophthalmology 2007; 114: 440-5.

4. Robert PY, Dubois A, Chaignier D, Garnier F, Ploy MC. Investigation of bacterial contamination of corneal donors using molecular biology. Acta Ophthalmol 2012 90: S249.

5. European Committee on Antimicrobial Susceptibility Testing (EUCAST): antimicrobial susceptibility testing. www.eucast.org/ast_of_bacteria.

6. South Eastern Sydney Local Health District (SESLHD): Sydney Eye Hospital and Lions NSW Eye Bank develop new corneal storage technique - eliminating waiting list for corneal transplantation. 2013. www.seslhd. health.nsw.gov.au.

7. Baer JC, Nirankari VS, Glaros DS. Streptococcal endophthalmitis from contaminated donor corneas after keratoplasty - clinical and laboratory investigations. Arch Ophthalmol 1988; 106: 517-20.

8. Fong LP, Gladstone D, Casey TA. Corneo-scleral rim cultures: donor contamination - a case of fungal endophthalmitis transmitted by K-Sol stored cornea. Eye 1988; 2: 670-6

9. Hassan SS, Wilhelmus KR, Dahl P, et al. Medical Review Subcommittee of the Eye Bank Association of America. Infectious disease risk factors of corneal graft donors. Arch Ophthalmol 2008; 126: 235-9.

10. Sousa LB, Solari H, Freitas D, Hofling-Lima A, Yu CM. Clinical-laboratorial evaluation of Streptococcus' keratitis after corneal transplantation. Invest Ophthalmol Vis Sci 2004; 45: E-abstract 4976.

11. Cameron JA, Badr IA, Miguel Risco J, Abboud E, Gonnah el S. Endophthalmitis cluster from contaminated donor corneas following penetrating keratoplasty. Can J Ophthalmol 1998; 33: 8-13.

12. Oguido APMT, Casella AMB, Hofling-Lima AL, Pacheco SA, Bispo PJM, Marques F. Pseudomonas aeruginosa en dophthalmitis after penetrating keratoplasty transmitted from the same donor to two recipients confirmed by pulsed-field gel electrophoresis. J Clin Microbiol 2011; 49: 3346-7.

13. Levartovsky S, Lazarovich A. Devastating endophthalmitis caused by Serratia marcescens in two recipients after transplantation of corneal grafts from the same donor. Cell Tissue Bank 2002; 3: 45-7.

14. Tsuru T, Sawa M. Bacteriological study of donor corneas. Folia Ophthalmol Jap 1989; 40: 1230-5.

15. Morel P, Roubi N, Bertrand X, et al. Bacterial contamination of a cornea tissue bank: implications for the safety of graft engineering. Cornea 2003; 22: 221-5.

16. Tappeiner C, Goldblum D, Zimmerli S, Fux C, Frueh BE. Donor-to-host transmission of Candida glabrata to both recipients of corneal transplants from the same donor. Cornea 2009; 28: 228-30.

17. Jafarinasab MR, Feizi S, Yazdizadeh F, Kanavi MR, Moein HR. Aspergillus flavus keratitis after deep anterior lamellar keratoplasty. J Ophthal Vision Res 2012; 7: 167-71.

18. Suthpin JE, Pfaller MA, Hollis RJ, Wagoner MD. Donorto-host transmission of Candida albicans after corneal transplantation. Am J Ophthalmol 2002; 134: 120-1.

19. Hsu YJ, Huang JS, Tsai JH, Hu FR, Hou YC. Early-onset severe donor-related Candida keratitis after Descemet stripping automated endothelial keratoplasty. J Formos Med Assoc 2014; 113: 874-6.
20. Harris DJ, Stulting RD, Waring GO $3^{\text {rd }}$, Wilson LA. Late bacterial and fungal keratitis after corneal transplantation. Spectrum of pathogens, graft survival, and visual prognosis. Ophthalmology 1988; 95: 1450-7.

21. Keyhani K, Seedor JA, Shah MK, Terraciano AJ, Ritterband $D C$. The incidence of fungal keratitis and endophthalmitis following penetrating keratoplasty. Cornea 2005; 24: 288-91.

22. Ritterband DC, Shah MK, Meskin SW, et al. Efficacy and safety of voriconazole as an additive in Optisol GS a preservation medium for corneal donor tissue. Cornea 2007; 26: 343-7.

23. Wesolowska M, Knys B, Reich A, et al. Prevalence of Demodex spp. in eyelash follicles in different populations. Arch Med Sci 2014; 10: 319-24.

24. Hamrah P, Huq SO, Liu Y, Zhang O, Dana MR. Corneal immunity is mediated by heterogeneous population of antigen-presenting cells. J Leukoc Biol 2003; 74: 172-8.

25. Kubicka-Sierszen A, Grzegorczyk Jt. The influence of infectious factors on dendritic cell apoptosis. Arch Med Sci 2015; 11: 1044-51. 